\title{
Ischemic Heart Disease in Patients with Diabetes Mellitus
}

Review article

Authors: (1) Alaa Ahmed Ghaleb Ali,(2) ElhamomarHamed, (3)Ahmed Mohamed Boghdady,(4)Hassan Ahmed HassaneinShehata.

(1)Internal Medicine Department, Faculty of Medicine, Sohag University.

(2)Asssociate Professor of Clinical Pathology, Faculty of Medicine, Sohag University.

(3) Professor of Internal Medicine, Faculty of Medicine, Sohag University.

(4)Professor of Internal Medicine, Faculty of Medicine, Sohag University.

Cardiovascular diseases (CVD), comprising coronary heart (CHD) and cerebrovascular diseases, are currently the leading cause of death globally, accounting for $21.9 \%$ of total deaths, and are projected to increase to $26.3 \%$ by 2030 (WHO Press; 2008). These are not new risks, but the ubiquity of smoking, dyslipidaemia, obesity, diabetes, and hypertension has been gradually escalating (Gupta et al ., 2008),

In addition, a complex mix of mechanistic processes such as oxidative stress, enhanced atherogenecity of cholesterol particles, abnormal vascular reactivity, augmented haemostatic activation, and renal dysfunction have been proposed as features characteristic of T2DM that may confer excess risk of CHD (Deedwania et al., 2005). People of Indian Asian descent make up over a fifth of the world's population, combining inhabitants of the subcontinent and the Indian diaspora living elsewhere.

The so-called "Asian Indian Phenotype" refers to an amalgamation of clinical (larger waist-to-hip and waist-to-height ratios signalling excess visceral adiposity), biochemical (insulin resistance, lower adiponectin, and higher C-reactive protein levels) and metabolic abnormalities [raised triglycerides, low high-density lipoprotein (HDL) cholesterol] that are more prevalent in individuals of South Asian origin and predispose this group to developing diabetes and premature CHD (Enas et al., 1993: Mohan et al., 2007).

It is expected that individuals of Indian Asian ethnicity will account for between 40$60 \%$ of global CVD burden within the next 10-15 years (Gaziano et al., 2006). The astonishingly higher risk in this particular ethnic group has been attributed to underlying genetic susceptibility (Radha et al., 2007\& Chambers et al., 2008) unmasked by environmental factors (permeation of contemporary lifestyle practices) (Gupta et al., 2006) or intrauterine programming which predisposes to asymmetric energy metabolism and rapid, excess accumulation of visceral body fat in adult life (Lev-Ran ., 2001: Yajnik ., 2004).

In terms of absolute numbers of individuals with diabetes, India, Pakistan and Bangladesh make up three of the top ten countries globally (Wild et al., 2004) and together, the region with the highest number of diabetes-related deaths currently (International Diabetes Federation (IDF)., 2009). India alone is estimated to have 50.8 million inhabitants with diabetes, the most of any country worldwide (International Diabetes Federation (IDF)., 2009).

Propelled by socio-economic transformation, population ageing, burgeoning levels of overweight (Gupta et al., 2006) and proliferation of individuals and children with prediabetes (impaired glucose regulation) (Mohan,et al., 2007), increase in T2DM (Gupta et al., 2008) and CHD4 will result in even greater future burdens.

The proportion of coronary disease patients with diabetes varies across countries, but approximately one-fifth of clinical trial (18\%) (McGuire et al., 2000) and registry 
patients (15.1-21.4\%) (Prabhakaran et al., 2005) are documented as known diabetes patients. India stands out as an anomaly with $30.4 \%$ (Xavier et al., 2008) and $39.1 \%$ (Prabhakaran et al., 2005) of CHD patients reporting known diabetes in national and international prospective registries.

These proportions may be deemed the result of high background prevalence of glucose abnormalities in India. However, given that South Asians have higher prevalence of cardiovascular risk factors (Ramachandran et al., 1998\& Joshi et al., 2007), higher prevalence of T2DM, and earlier onset of CHD despite a normal body mass index (BMI) by international standards (Ghaffar et al., 2004\& Diaz et al., 2007), the premise that this population is more susceptible to diabetes and CVD, and that these conditions are interlinked, is plausible.

Though previously CHD and T2DM were considered mainly diseases of affluence, reversal of socio-economic gradient in these diseases is starting as lower socioeconomic groups in South Asia are exhibiting ever-increasing risk (Misra et al., 2001\& Gupta et al., 2003). In addition, characteristic disparities (rural-urban split, public-private health care and low awareness) that are pervasive across the region, combined with chronicity and asymptomatic nature (silent killer) of noncommunicable risk factors and diseases, perpetuate delays in diagnosis, inertia to seek care, and effective self-management of risks.

Risk factor control in cardiovascular disease reduction:

There is evidence that lifestyle modification (regular, moderate physical activity and healthy dietary habits) has a sustained effect on reducing incidence of diabetes (Lindstrom et al., 2006: Knowler et al., 2009), and helps reduce the occurrence and mortality of CVD events in people with and without established CHD (Mozaffarian et al., 2008).

Iestra and colleagues (Iestra et al., 2005) have shown relative risk of mortality is reduced in the general population that stop smoking (up to 50\% reduction), engage in moderate physical activity (20-30\%), and adopt a combination of healthy dietary habits (limited intake of saturated fats, regular fish consumption, sufficient fruit and vegetable intake, and limited salt consumption - together, $15-40 \%$ reduction).

Randomized clinical trials evaluating individual risk factor control with pharmaceutical agents in patients with diabetes have also demonstrated reduction in surrogate markers, which translated into lower incidence of cardiovascular events and mortality. These findings have been utilized to institute clinical practice guidelines and standards of care based on strength of evidence and cost-effectiveness of interventions.

HMG-CoA reductase inhibitors (statins) in particular, have indisputable proven efficacy, demonstrating $27-40 \%$ reductions in LDL-cholesterol in all placebocontrolled trials, and subsequent decreases in occurrence of cardiovascular events and mortality by 25 to $42 \%$ (Colhoun et al., 2004\& Collins et al., 2005) in persons with and without diabetes or previous acute coronary syndrome (ACS). This benefit extends to those with already controlled LDL-cholesterol fractions (Baigent et al., 2005).

Since the evidence in favour of lowering LDL is so overwhelming (Baigent et al., 2005) and similar findings are awaited for triglyceride management and elevating HDL (Singh et al., 2007;Ginsberg et al., 2007), the primary emphasis of lipid management tends to focus on LDL. Dietary modification (Manley et al., 2007) and addition of statins are, therefore, recommended as first-line management guidelines for lipid control in diagnosed diabetes patients or those with confirmed CVD. 
Hypertension co-exists in a significant proportion of people with diabetes (Kempler.et al., 2005). Lowering blood pressure (BP) produces dramatic benefits in these subjects and BP targets have been modified specifically to avert disabling and fatal complications in the form of nephropathy, retinopathy, and vascular events (Adler et al., 2000).

Several large randomized trials, sub-studies (Adler et al., 2000: Whelton et al., 2005), and meta-analyses (Collins et al., 1990\& Turnbull et al., 2005) which include patients with diabetes have shown benefit in reducing non-fatal myocardial infarction, chronic kidney disease (Estacio et al., 2006), and remarkable reductions in cardiovascular (51\%) (Hansson et al., 1998) and all-cause mortality.

The use of renin-angiotensin system (RAS) modifying agents [angiotensin-converting enzyme inhibitors (ACEi) or angiotensin-II receptor blockers (ARB)] provide ancillary benefits in forestalling renal complications on top of BP control, and have additionally demonstrated lower composite CVD outcomes in numerous randomized trials, even after adjustment for changes in BP (Pahor et al., 2000: Chalmers et al., 2008).

These cardio- and reno-protective effects (anti-atherosclerotic, reducing arterial stiffness, and improving endothelial function) (Vijayaraghavan et al., 2005) are motivating more extensive application of RAS-modifier agents in patients with diabetes. Previous evidence has also demonstrated the efficacy of low-dose daily aspirin use in preventing CVD events, especially secondary prevention in those that have already suffered previous events (Antithrombotic Trialists Collaboration., 2002).

However, a large meta-analysis (Baigent et al., 2009) cautions that ubiquitous use of low-dose aspirin for primary prevention may only be justified where net benefits of preventing coronary events in high-risk patients outweigh the increased risk of gastrointestinal and extra-cranial bleeds. As such, this study showed no significant effects on preventing first onset of stroke. The addition of clopidogrel is also recommended only for prevention of recurrent events (Bhatt et al., 2002).

Glycaemic control in cardiovascular risk reduction: an actively evolving paradigm:

In patients with diabetes, where excess CVD risk has already been demonstrated, the relationship between glycaemia itself and CVD should not, theoretically, be in doubt. Even studies in non-diabetic subjects, have shown an association between fasting blood glucose and CVD. Another meta-analysis of prospective cohort studies (Selvin et al., 2004) examined glycosylated haemoglobin (HbA1c a more stable, accurate, less error-prone measure of long-term glycaemic levels) and CVD in persons with diabetes and found 18 per cent (pooled RR 1.18; 95\% CI 1.10 to 1.26) and 15\% (pooled RR $1.15 ; 95 \%$ CI 0.92 to 1.43 ) greater relative risk per $1 \%$ increase in HbA1c in T2DM and T1DM, respectively.

However, the converse of this association, whether reducing glucose levels to nearnormal targets results in lower CVD events, is still a controversial topic. Despite impressive reduction in microvascular complications (Reichard et al., 1993) and retrospective cohort data showing lower risk of strokes (21\%) and MI (23\%) (Lawes et al., 2004) with lower levels of glycaemia, the early prospective trial data evaluating macrovascular outcomes classically provided equivocal results $[$ e.g. $16 \%(P=0.052)$ non-significant reduction in MI in United Kingdom Prospective Diabetes Study (UKPDS)], citing reasons of inadequate power, follow-up or design deficiencies. More recent multi-centre trials sought to conclusively evaluate the influence of 
achieving lower therapeutic targets for glycaemic control on the incidence of CVD endpoints.

Since a variety of pharmacological and non-pharmacological treatments are established, cost-effective, and safe interventions for glycaemic control (Narayan et al., 2006), the more contemporary theme of what level of glycaemia to achieve holds topical interest, requiring more in-depth discussion. Three large prospective randomized trials attempted to definitively address the glycaemia and CVD debate.

The Action to Control Cardiovascular Risk in Diabetes (ACCORD) (Gerstein et al., 2008), Action in Diabetes and Vascular Disease: Preterax and Diamicron Modified Release Controlled Evaluation (ADVANCE) (Patel et al., 2008), and Veterans Affairs Diabetes Trial (VADT) (Duckworth et al., 2009) studies randomized 10251, 11140, and 1791 T2DM patients, respectively, with co-existing risk factors and/or history of diabetic complications (including previous CVD events) into intensive (aiming for bold "near-normal" glycaemic targets) or conventional therapy groups, using different treatment regimens.

After a 1.1 per cent relative difference in median HbA1c between the groups (6.4 vs. $7.5 \%$ ) and 3.5 years of follow-up, ACCORD was prematurely discontinued due to 54 excess deaths in the intensive therapy arm. The ADVANCE trial achieved a 0.8 per cent lower median HbA1c $(6.5 \%)$ in the intensive therapy arm compared to the standard group over a 5 year follow-up period and demonstrated a 10 per cent reduction in composite of major micro- and macro-vascular events (HR 0.90, 95\% CI 0.82 to $0.98 ; P=0.01$ ), which did not remain significant after adjustment for reduction in nephropathy ( $21 \%$ reduction in intensive therapy group; HR $0.79,95 \%$ CI 0.66 to $0.93 ; P=0.006)$.

From a baseline median HbA1c level of 9.4 per cent, the VADT achieved A1c levels of 6.9 and 8.4 per cent in the intensive and standard groups, respectively (Gerstein et al., 2008). However, there was no significant between-group difference in the composite primary outcome (HR $0.88 ; 95 \% \mathrm{CI}, 0.75$ to $1.05 ; P=0.14$ ), nor in the number of new, or progression of, microvascular complications. Across these three studies, the intensive therapy arms all reported higher incidence of hypoglycaemia requiring medical assistance and weight gain among participants.

Despite seemingly negative results, there are several points from these study results that should be kept in perspective, especially as outcomes of ongoing trials will continue to emerge at regular intervals in the future (Buse et al., 2005). Firstly, diabetes is still the leading cause of adult-onset blindness, end-stage renal disease, and non-traumatic lower-extremity amputations worldwide, (Vinik et al., 2003), and glycaemic control overwhelmingly reduces these microvascular complications.

Therefore, blood glucose management remains a vital component of preventing disabling and fatal target organ damage in both T1DM and T2DM. Secondly, optimal glycaemic targets have been chosen based on this evidence from microvascular risk reduction and should at least be deemed appropriate considering the increased risks of hypertension, dyslipidaemia, and hyper homocysteinaemia - themselves strong risks for CVD - which are associated with renal insufficiency. However, in the broader context of CVD prevention and considering the severity of chronic kidney disease, these targets may need to be customized according to individual risk (Srikanth\& Deedwania ., 2005).

Other important considerations include the fact that participants in these large trials were high-risk patients with poor baseline control, high pre-existing use of insulin (among 35-50\% of subjects), and a third (32-40\%) already had pre-existing heart disease. Indeed, the average duration of diabetes (8.5-11 yr) must also weigh in as a 
factor, which motivates the assertion that either earlier (Deedwania et al., 2005), or more sustained intervention is required to reduce the risk of prolonged metabolic disturbance.

This was confirmed in the 17 yr follow-up of the Diabetes Control and Complications Trial (DCCT) (Nathan et al., 2005) where the intensively treated type 1 diabetes patients had 42 and 57 per cent lower risk of CVD events and death from CVD, respectively, despite no difference found at earlier follow-up. The UKPDS ten-year follow-up (Holman et al., 2008) also demonstrated delayed beneficial effects of early initiation of glycaemic control on macrovascular outcomes, a "metabolic memory" of sorts.

In addition to greater frequency of hypoglycaemia and weight gain in the intensive group participants, it has been postulated that serious adverse events and mortality may be attributable to more aggressive and rapid (e.g., ACCORD and VADT permitted any drug combination with rapid glucose-lowering) than measured (e.g., ADVANCE used sulphonylureas with gradual between-group differences in glycaemia) glucose-lowering; however, there are currently no data to support this assertion.

Another published meta-analyses (Ray et al., 2009\& Turnbull et al., 2009) have sought to examine the data in its entirety, pooling data and performing several prespecified sub-analyses. The findings seem to conclude that intensive glucose lowering may have significant benefits in preventing coronary events, especially in those without pre-existing established atherosclerotic vascular disease; however, there is seemingly no mortality-reducing benefit from targeted glucose management.

Based on the totality of evidence available, the American Diabetes Association, American College of Cardiology, and American Heart Association jointly issued recommendations (Skyler et al., 2009) to assuage uncertainty and confusion that emerged among clinicians and scientists following the release of these trial results. Broadly, current guidelines support customizing the intensity of glucose management depending on individual patient characteristics and co-morbidities.

A final and very convincing point is that glycaemia is not the sole consideration in CVD risk, but rather plays a role in the confluence of multi-factorial influences (Haffner et al., 2003). Therefore, exclusively concentrating on glucose control may be a key limitation of these focused randomized trials.

A meta-analysis which presented a substantial 27 per cent greater risk for CVD between the highest $(8.3-10.8 \mathrm{mmol} / \mathrm{l})$ and lowest $(3.8-5.9 \mathrm{mmol} / \mathrm{l})$ post-challenge blood glucose levels, subsequently also revealed significant attenuation of risk (to 19\%) when adjustment was made for co-existing CVD risk factors (Levitan et al., 2004).

Progression of carotid atherosclerosis in diabetes patients showed analogous attenuation upon controlling for other CVD risks (Wagenknecht et al., 2003). By aggressively managing all modifiable risk factors (blood pressure and lipid control) (Vijan et al., 2003) and implementing evidence-based guidelines (American Diabetes A., 2009) vascular events and mortality can be reduced.

Monitoring performance through audits and quality of care indicators will both improve diabetes care but also motivate local standards of care, quality improvement and encourage physicians to strive to enhance their reputations considerably (Gaede et al., 2003). Also, within these large trials of glycemic control, embedded trials were conducted to examine the effect of targeted, rigorous treatment of co-morbid risk factors on event rates; results from these trials are eagerly anticipated. 
A good example of comprehensive risk factor control is the Steno-II study investigated integrated, comprehensive, intensified risk factor control in a randomized fashion in Danish T2DM patients with microalbuminuria. They demonstrated declines in metabolic parameters (including $\mathrm{HbA1c}$ values) which translated into sizeable gains in prevention of CVD (53\%) over 7.8 and lower mortality from cardiovascular events (59\%) over 13.3 years of follow-up (Gaede et al., 2003).

\section{References:}

1. World Health Organization. World Health Statistics. Department of Measurement \& Health Information Systems of the Information, Evidence and Research Cluster. Geneva: WHO Press; 2008. p. 29-31.

2. Adler AI, Stratton IM, Neil HA, Yudkin JS, Matthews DR, Cull CA, et al. Association of systolic blood pressure with macrovascular and microvascular complications of type 2 diabetes (UKPDS 36): prospective observational study. BMJ 2000; 321 : 412-9.

3. American Diabetes A. Standards of Medical Care in Diabetes--2008. Diabetes Care 2008; 31 (Suppl 1): S1254.

4. American Diabetic Association: Standards of medical care in diabetes2009. Diabetes Care 2009;32(suppl 1):S13-S61.

5. Antithrombotic Trialists Collaboration. Collaborative meta-analysis of randomised trials of antiplatelet therapy for prevention of death, myocardial infarction, and stroke in high risk patients. BMJ 2002; 324 : 7186.

6. Baigent C, Blackwell L, Collins R, Emberson J, Godwin J, Peto R, et al. Aspirin in the primary and secondary prevention of vascular disease: collaborative meta-analysis of individual participant data from randomised trials. Lancet 2009; 373 : 1849-60.

7. Baigent $\mathrm{C}$, Keech A, Kearney PM, Blackwell L, Buck G, Pollicino C, et al. Efficacy and safety of cholesterollowering treatment: prospective metaanalysis of data from 90,056 participants in 14 randomised trials of statins. Lancet 2005; 366 : 1267-78.
8. Bhatt DL, Marso SP, Hirsch AT, Ringleb PA, Hacke W, Topol EJ. Amplified benefit of clopidogrel versus aspirin in patients with diabetes mellitus. Am J Cardio 2002; 90 : 6258.

9. Buse JB, Rosenstock J. Prevention of cardiovascular outcomes in type 2 diabetes mellitus: trials on the horizon. Endocrinol Metab Clin North Am 2005; 34 : 221-35.

10.Chalmers J, Joshi R, Patel A. Advances in reducing the burden of vascular disease in type 2 diabetes. Clin Exp Pharmacol Physiol 2008; 35 : 434-7.

11.Chambers JC, Elliott $P$, Zabaneh D, Zhang $\mathrm{W}, \mathrm{Li} \mathrm{Y}$, Froguel $\mathrm{P}$, et al. Common genetic variation near MC4R is associated with waist circumference and insulin resistance. Nat Genet 2008; $40: 716-8$.

12. Colhoun HM, Betteridge DJ, Durrington PN, Hitman GA, Neil HA, Livingstone SJ, et al. Primary prevention of cardiovascular disease with atorvastatin in type 2 diabetes in the Collaborative Atorvastatin Diabetes Study (CARDS): multicentre randomised placebo-controlled trial. Lancet 2004; $364:$ 685-96.

13. Collins R, Armitage J, Parish S, Sleigh P, Peto R; MRC/BHF Heart Protection Study of cholesterol-lowering with simvastatin in 5963 people with diabetes: a randomised placebocontrolled trial. Lancet 2003; 361 : 2005-16.

14.Collins $R$, Peto $R$, MacMahon $S$, Hebert P, Fiebach NH, Eberlein KA, et al. Blood pressure, stroke, and coronary heart disease. Part 2, Shortterm reductions in blood pressure: overview of randomised drug trials in their epidemiological context. Lancet $1990 ; 335$ : 827-38. 
15.Deedwania PC, Fonseca VA. Diabetes, prediabetes, and cardiovascular risk: shifting the paradigm. Am J Med 2005; 118 : 939-47.

16.Diaz VA, Mainous AG, 3rd, Baker R, Carnemolla M, Majeed A. How does ethnicity affect the association between obesity and diabetes? Diabet Med 2007; 24 : 1199-204.

17.Duckworth W, Abraira C, Moritz T, Reda D, Emanuele N, Reaven PD, et al. Glucose control and vascular complications in veterans with type 2 diabetes. N Engl J Med 2009; 360 : 129-39.

18.Enas EA, Mehta J. Malignant coronary artery disease in young Asian Indians: thoughts on pathogenesis, prevention, and therapy. Coronary Artery Disease in Asian Indians (CADI) Study. Clin Cardiol 1993; $18: 131-5$.

19. Estacio RO, Coll JR, Tran ZV, Schrier $\mathrm{RW}$. Effect of intensive blood pressure control with valsartan on urinary albumin excretion in normotensive patients with type 2 diabetes. Am J Hypertens 2006; 19 : 1241-8.

20. Gaede P, Vedel P, Larsen N, Jensen $\mathrm{GV}$, Parving $\mathrm{HH}$, Pedersen $\mathrm{O}$ : Multifactorial intervention and cardiovascular disease in patients with type 2 diabetes. N Engl J Med 348: 383-393, 2003.

21.Gaziano TA, Reddy KS, Paccaud F, Horton S, Chaturvedi V. Cardiovascular Disease. In: Jamison DT, Breman JG, Measham AR, Alleyne G, Claeson M, Evans DB, et al, editors. Disease control priorities in developing countries, 2nd ed. New York: Oxford University Press; 2006. p. 645-62.

22. Gerstein HC, Miller ME, Byington RP, Goff DC Jr, Bigger JT, Buse JB, et al. Effects of intensive glucose lowering in type 2 diabetes. N Engl J Med 2008; $358: 2545-59$.

23. Ghaffar A, Reddy KS, Singhi $M$. Burden of non-communicable diseases in South Asia. BMJ 2004; 328 : 80710.

24.Ginsberg HN, Bonds DE, Lovato LC, Crouse JR, Elam MB, Linz PE, et al. Evolution of the Lipid Trial Protocol of the Action to Control Cardiovascular Risk in Diabetes (ACCORD) Trial. Am J Cardiol 2007; 99 (Suppl 1): S56S67.

25.Gupta M, Brister S. Is South Asian ethnicity an independent cardiovascular risk factor? Can J Cardiol 2006; 22 : 193-7.

26.Gupta R, Gupta VP, Sarna M, Prakash H, Rastogi S, Gupta KD. Serial epidemiological surveys in an urban Indian population demonstrate increasing coronary risk factors among the lower socioeconomic strata. J Assoc Physicians India 2003; 51 : 4707

27.Gupta R, Joshi P, Mohan V, Reddy KS, Yusuf S. Epidemiology and causation of coronary heart disease and stroke in India. Heart 2008; 94 : 16-26.

28.Gupta R, Kumar P. Global diabetes landscape - Type 2 diabetes mellitus in south Asia: Epidemiology, risk factors, and control. Insulin 2008; 3 : 78-94.

29.Haffner SJ, Cassells H. Hyperglycemia as a cardiovascular risk factor. Am J Med 2003; 115 (Suppl 8A): 6S-11S.

30.Hansson L, Zanchetti A, Carruthers SG, Dahlof B, Elmfeldt D, Julius S, et al. Effects of intensive blood-pressure lowering and low-dose aspirin in patients with hypertension: principal results of the Hypertension Optimal Treatment (HOT) randomised trial. HOT Study Group. Lancet 1998; 351 : 1755-62.

31.Holman RR, Paul SK, Bethel MA, Matthews DR, Neil HA. 10-year follow-up of intensive glucose control in type 2 diabetes. N Engl J Med 2008; 359: 1577-89.

32.Iestra JA, Kromhout D, van der Schouw YT, Grobbee DE, Boshuizen HC, van Staveren WA. Effect size estimates of lifestyle and dietary changes on all-cause mortality in coronary artery disease patients: a systematic review. Circulation 2005; $112: 924-34$.

33.International Diabetes Federation (IDF). Diabetes atlas 4th ed. 2009. Available at: www.diabetesatlas.org.

34.Joshi $\mathrm{P}$, Islam $\mathrm{S}$, Pais $\mathrm{P}$, Reddy $\mathrm{S}$, Dorairaj P, Kazmi K, et al. Risk factors 
for early myocardial infarction in South Asians compared with individuals in other countries. JAMA 2007; 297 : 286-94.

35.Kempler P. Learning from large cardiovascular clinical trials: classical cardiovascular risk factors. Diabetes Res Clin Pract 2005; 68 (Suppl 1): S43-7.

36. Knowler WC, Fowler SE, Hamman RF, Christophi CA, Hoffman HJ, Brenneman AT, et al. 10-year followup of diabetes incidence and weight loss in the Diabetes Prevention Program Outcomes Study. Lancet 2009; $374: 1677-86$.

37. Lawes CM, Parag V, Bennett DA, Suh I, Lam TH, Whitlock G, et al. Blood glucose and risk of cardiovascular disease in the Asia Pacific region. Diabetes Care 2004; 27 : 2836-42.

38.Levitan EB, Song Y, Ford ES, Liu S. Is nondiabetic hyperglycemia a risk factor for cardiovascular disease? A meta-analysis of prospective studies. Arch Intern Med 2004; 164 : 2147-55.

39.Lev-Ran A. Human obesity: an evolutionary approach to understanding our bulging waistline. Diabetes Metab Res Rev 2001; 17 : 347-62.

40.Lev-Ran A. Human obesity: an evolutionary approach to understanding our bulging waistline. Diabetes Metab Res Rev 2001; 17 : 347-62.

41.Lindstrom $J$, Ilanne-Parikka $P$, Peltonen M, Aunola S, Eriksson JG, Hemio K, et al. Sustained reduction in the incidence of type 2 diabetes by lifestyle intervention: follow-up of the Finnish Diabetes Prevention Study. Lancet 2006; 368 : 1673-9.

42. Manley SE, Stratton IM, Cull CA, Frighi V, Eeley EA, Matthews DR, et al. Effects of three months' diet after diagnosis of Type 2 diabetes on plasma lipids and lipoproteins (UKPDS 45). UK Prospective Diabetes Study Group. Diabet Med 2000; 17 : 518-23.

43. McGuire DK, Emanuelsson $\mathrm{H}$, Granger CB, Magnus Ohmn E, Moliterno DJ, White HD, et al. Influence of diabetes mellitus on clinical outcomes across the spectrum of acute coronary syndromes. Findings from the GUSTO-IIb study. GUSTO IIb Investigators. Eur Heart J 2000; 21 : 1750-8.

44.Misra A, Pandey RM, Devi JR, Sharma R, Vikram NK, Khanna N. High prevalence of diabetes, obesity and dyslipidaemia in urban slum population in northern India. Int $\mathrm{J}$ Obes Relat Metab Disord 2001; 25 : 1722-9.

45.Mohan V, Jaydip R, Deepa R. Type 2 diabetes in Asian Indian youth. Pediatr Diabetes 2007; 8 (Suppl 9): 28-34.

46. Mohan V, Sandeep S, Deepa R, Shah B, Varghese C. Epidemiology of type 2 diabetes: Indian scenario. Indian J Med Res 2007; 125 : 217-30.

47.Mozaffarian D, Wilson PWF, Kannel WB. Beyond established and novel risk factors: Lifestyle risk factors for cardiovascular disease. Circulation 2008; $117: 3031-8$.

48. Narayan KMV, Zhang P, Kanaya AM. Williams DE, Engelgau MM,. Imperatore G, et al. Diabetes: The Pandemic and Potential Solutions. In: Jamison DT, Breman JG, Measham $\mathrm{AR}$, et al, editors. Disease control priorities in developing countries, 2nd ed. New York: Oxford University Press; 2006:tables 30.33 and 30.34.

49.Nathan DM, Cleary PA, Backlund JY, Genuth SM, Lachin JM, Orchard TJ, et al. Intensive diabetes treatment and cardiovascular disease in patients with type 1 diabetes. N Engl J Med 2005; $353: 2643-53$.

50.Pahor M, Psaty BM, Alderman MH, Applegate WB, Williamson JD, Furberg CD. Therapeutic benefits of ACE inhibitors and other antihypertensive drugs in patients with type 2 diabetes. Diabetes Care 2000; $23: 888-92$.

51.Patel A, MacMahon $S$, Chalmers $\mathrm{J}$, Neal B, Billot L, Woodward M, et al. Intensive blood glucose control and vascular outcomes in patients with type 2 diabetes. N Engl J Med 2008; 358 : 2560-72.

52.Prabhakaran D, Yusuf $S$, Mehta $S$, Pogue J, Avezum A, Budaj A, et al. Two-year outcomes in patients 
admitted with non-ST elevation acute coronary syndrome: results of the OASIS registry 1 and 2. Indian Heart $\mathbf{J}$ 2005; $57: 217-25$.

53.Radha V, Mohan V. Genetic predisposition to type 2 diabetes among Asian Indians. Indian $\mathrm{J}$ Med Res 2007; $125: 259-74$.

54.Ramachandran A, Snehalatha C, Latha E, Satyavani K, Vijay V. Clustering of cardiovascular risk factors in urban Asian Indians. Diabetes Care 1998; 21 : 967-71.

55.Ray KK, Seshasai SRK, Wijesuriya S, SivakuumaranR, Nethercott S, Preiss $D$, et al. Effect of intensive control of glucose on cardiovascular out comes and death in patients with diabetes mellitus: a meta-analysis of randomized controlled trials. Lancet 2009; 373: 1765-72.

56. Reichard P, Nilsson BY, Rosenqvist U. The effect of long-term intensified insulin treatment on the development of microvascular complications of diabetes mellitus. N Engl J Med 1993; 329 : 304-9.

57.Selvin E, Coresh J, Wattanakit K, Steffes MW, Sharrett R. HbA1c and Peripheral arterial disease in diabetes, The ARIC Study. Diabetes Care 2004; 29:877-82.

58. Singh IM, Shishehbor MH, Ansell BJ. High-density lipoprotein as a therapeutic target: a systematic review. JAMA 2007; 298 : 786-98.

59. Skyler JS, Bergenstal R, Bonow RO, Buse J, Deedwania P, Gale EA, et al. Intensive glycemic control and the prevention of cardiovascular events: implications of the ACCORD, ADVANCE, and VA diabetes trials: a position statement of the American Diabetes Association and a scientific statement of the American College of Cardiology Foundation and the American Heart Association. Diabetes Care 2009; 32 : 187-92.

60. Srikanth S, Deedwania P. Comprehensive risk reduction of cardiovascular risk factors in the diabetic patient: an integrated approach. Cardiol Clin 2005; 23 : 193210.
61.Turnbull F, Neal B, Algert C, Chalmers J, Chapman N, Cutler J, et al. Effects of different blood pressurelowering regimens on major cardiovascular events in individuals with and without diabetes mellitus: results of prospectively designed overviews of randomized trials. Arch Intern Med 2005; 165 : 1410-9.

62.Vijan S, Hayward RA. Treatment of Hypertension in Type 2 Diabetes Mellitus: Blood Pressure Goals, Choice of Agents, and Setting Priorities in Diabetes Care. Ann Intern Med 2003; $138: 593-602$.

63.Vijayaraghavan K, Deedwania PC. The renin angiotensin system as a therapeutic target to prevent diabetes and its complications. Cardiol Clin 2005; $23:$ 165-83.

64.Vinik AI, Vinik E. Prevention of the complications of diabetes. Am J Managed Care 2003; 9 (3 Suppl): S6380.

65.Wagenknecht LE, Zaccaro D, Espeland MA, Karter AJ, O'Leary DH, Haffner SM. Diabetes and progression of carotid atherosclerosis: the insulin resistance atherosclerosis study. Arterioscler Thromb Vasc Biol 2003; $23: 1035-41$.

66. Whelton PK, Barzilay J, Cushman WC, Davis BR, Iiamathi E, Kostis JB, et al. Clinical outcomes in antihypertensive treatment of type 2 diabetes, impaired fasting glucose concentration, and normoglycemia: antihypertensive and lipid-lowering treatment to prevent heart attack trial (ALLHAT). Arch Intern Med 2005; $165: 1401-9$.

67.Wild S, Roglic G, Green A, Sicree R, King H. Global prevalence of diabetes: estimates for the year 2000 and projections for 2030. Diabetes Care 2004; 27 : 1047-53.

68.Xavier D, Pais P, Devereaux PJ, Xie C, Prabhakaran D, Reddy KS, et al. Treatment and outcomes of acute coronary syndromes in India (CREATE): a prospective analysis of registry data. Lancet 2008; $371: 1435$ 42. 
SOHAG MEDICAL JOURNAL

Vol. 22 No.1 Jan 2018

69. Yajnik CS. Early life origins of insulin resistance and type 2 diabetes in India
Ischemic Heart Disease in Patients with Diabetes Mellitus Alaa Ahmed Ghaleb

and other Asian countries. J Nutr 2004;

$134: 205-10$. 